\title{
PENINGKATAN KOMPETENSI PEDAGOGIK GURU SAINS SMP-SMA NEGERI 1 SESAYAP KABUPATEN TANA TIDUNG MELALUI SCIENCE TECHNOLOGY LITERACY (STL) DAN PENGEMBANGAN POTENSI LOKAL
}

\author{
Endik Deni Nugroho1a, Fadhlan Muchlas Abrori ${ }^{1}$
}

\begin{abstract}
Science teacher's role in improving the quality of learning is an urgent problem that must be realized. To encourage ongoing activities, the teacher needs to review / discuss activities, identify the obstacles programs that have been implemented, as well as practicing teachers' activities focused on developing lesson plans. Efforts that can be done is through mentoring and building-based learning Science Technology Literacy (STL) and the local potential. Some of the activities that have been carried out, namely socialization program, Counseling, Training, Mentoring, Teaching Dissemination of Results and Build Networking Skills. Based on the results of the activities as much as $60 \%$ of the 10 science teachers in SMP-SMA Negeri 1 Sesayap not understand the STL and the development of local potential. After the training and mentoring as many as 10 teachers have been able to make the device and implement STL learning and developing local potential in the classroom.
\end{abstract}

Keywords: Local Potential, Pedagogical Competence, Science Teacher, STL.

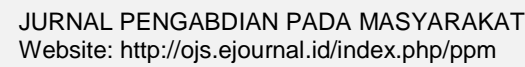

Permalink: http://ojs.ejournal.id/index.php/ppm/article/view/81

How to cite (APA): Nugroho, E. D., \& Abrori, F. M. (2017). Peningkatan kompetensi pedagogik guru sains SMP SMA Negeri Sesayap Kabupaten Tana Tidung melalui science technology literacy (STL) dan pengembangan potensi lokal. Jurnal Pengabdian Pada Masyarakat, 2(1), 19-28.

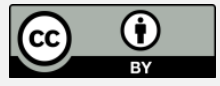

This is an open access article distributed under the terms of the Creative Commons Attribution 4.0 International License, which permits unrestricted use, distribution, and reproduction in any medium, provided the original work is properly cited.

\section{PENDAHULUAN}

Implementasi berbagai kurikulum seperti KBK sampai kurikulum 2013 sekarang ini seharusnya menuntut setiap sekolah menentukan muatanmuatan dalam kurikulum yang disesuaikan dengan satuan pendidikan, potensi/karakteristik daerah, sosial budaya masyarakat setempat, dan peserta didik di sekolah masing-masing. Kurikulum 2013 saat ini menuntut guru untuk berkreasi dalam menterjemahkan standar isi (Kompetensi inti dan Kompetensi Dasar) ke dalam muatan pembelajaran, mata pelajaran,

\footnotetext{
1 Program Studi Pendidikan Biologi, Universitas Borneo Tarakan.

a email: endwi.2011@gmail.com.
} 
beban belajar yang disesuaikan dengan kondisi objektif masing-masing satuan pendidikan. Pelaksanaan kurikulum saat ini menuntut kemandirian sekolah dan guru dalam menyusun perangkat pelaksanaannya.

Bagi guru, menganalisis SK/kompetensi inti, KD, merumuskan indikator, menyusun silabus, menyiapkan rencana pelaksanaan pembelajaran (RPP) merupakan hal baru yang memerlukan panduan dan pendampingan yang efektif. Guru-guru perlu berkolaborasi untuk menyusun perangkatperangkat dan melaksanakan pembelajaran inovatif. Dengan cara ini, diharapkan kualitas proses dan hasil pembelajaran dapat ditingkatkan dan pada akhirnya kualitas pendidikan dapat meningkat.

Pengembangan kualitas pembelajaran dan pengembangan model-model pembelajaran dirasakan sangat diperlukan guru dalam menjalankan tugas sehari-hari. Selama ini masih banyak guru yang mengajar dengan cara konvensional, metode yang monoton dan berpusat pada guru. Untuk mewujudkan peran guru Sains dalam meningkatkan kualitas pembelajaran, maka peningkatan kinerja (Guru) merupakan masalah yang mendesak untuk dapat direalisasikan. Untuk mendorong berjalannya kegiatan Guru maka guru-guru perlu akan mengkaji/ membahas kegiatan Guru Sains, mengidentifikasi hambatan program Guru Sains yang telah dilaksanakan menwujudkan pembelajaran yang baik, serta mempraktikkan kegiatan Guru yang terfokus pada pengembangan rencana pembelajaran. Maka upaya yang dilakukan untuk meningkatkan kinerja Guru Sains dalam meningkatkan kualitas pembelajaran, yaitu melalui pendampingan dan membangun pembelajaran berbasis Science Technology Literacy (STL) dan potensi lokal.

Pengembangan biososial melalui Science Technology Literacy (STL) pada mata pelajaran Sains di SMP-SMA juga memungkinkan dengan memadukan strategi pembelajaran sebagai alternative pilihan. Namun, Problem Based Learning (PBL) atau Inquiry Based Learning dipandang contoh strategi pembelajaran yang cocok. PBL, yang sudah banyak dikenal para guru, dirancang tidak untuk membantu pembelajar memberikan informasi sebanyak-banyaknya kepada para siswa. Hal ini sesuai harapan implementasi kurikulum 2013 saat ini yang mengutamakan keterampilan proses.

Peranan pendampingan Guru Sains selain menggunakan Science Technology Literacy (STL), pola pembelajaran diarahkan memberikan karakter budaya yang bernilai tinggi dan termanfaatkannya kekayaan alam yang dikelola oleh putra-putri Indonesia hendaknya dapat direalisasikan. 
Pola pembelajaran yang memfasilitasi internalisasi budaya dan pemanfaatan potensi alam dapat dilakukan melalui Pendidikan berbasis keunggulan lokal. Pembelajaran berbasis keunggulan lokal adalah program pembelajaran yang diselenggarakan dengan memanfaatkan berbagai sumber daya dan potensi daerah yang bermanfaat bagi siswa dalam proses pengembangan kompetensi, yang selama ini dalam kenyataan di lapangan tidak terlaksana dalam menggali dan mengenalkan potensi lokal daerahnya.

Program ipteks bagi masyarakat ini bertujuan mendampingi guru-guru Sains SMP-SMA Negeri 1 KTT dalam meningkatkan kualitas proses kegiatan belajar mengajar dalam hal ini melalui menerapkan dan membuat Rancangan Pembelajaran pembelajaran berbasis STL dan potensi lokal memahamkan mereka mengenai tingkat dan kompleksitasnya permasalahan yang mungkin berkembang sebagai konsekuensi dari perkembangan ilmu Sains dan bioteknologi dalam kegiatan pembelajaran dikelas, isu ini tidak pernah disentuh atau diakomodasi.

Berdasarkan tujuan di atas, maka adanya program Ipteks bagi masyarakat diharapkan semua kegiatan tercapai dengan target luaran yang berupa: 1) Meningkatkan Kemampuan guru-guru Sains dalam membuat RPP dan meningkatkan kualitas pembelajaran berbasis STL dan potensi lokal; 2) Meningkatkan Keterampilan guru-guru Sains melalui GURU menggunakan dan mengembangkan pembelajaran berbasis STL dan potensi lokal sebagai sarana pendukung untuk menciptakan pembelajaran aktif, inovatif, kreatif, efektif, dan menyenangkan; dan 3) Pendampingan dan membangun Membangun Teaching Networking Skills dalam transfer pengetahuan dan teknologi dalam peranan LPTK Universitas Borneo Tarakan untuk mendorong peningkatan kemampuan intelektual calon guru terhadap disiplin ilmu yang digelutinya.

\section{METODE PELAKSANAAN}

Berdasarkan analisa permasalahan yang ada di SMP-SMA Negeri 1 Sesayap KTT tersebut, keberadaan guru-guru Sains selama ini terkesan "kurang optimal" dan belum memiliki peran yang bermakna dalam melakukan perubahan substansial dan mendasar dalam upaya meningkatkan mutu pendidikan dan kualitas pembelajaran. Tujuan sebenarnya menemukan permasalahan yang tidak bisa terpecahkan disekolah terkait dengan materi yang sulit, sehingga dengan adanya IbM ini bisa berembuk agar setiap permasalahan disekolah bisa direalisasikan 
tetapi kurang optimal. Oleh karena itu perlu pendampingan dan membantu guru-guru Sains melalui IbM dalam usaha meningkatkan kemampuan dan kualitas guru dengan diadakannya pendalaman materi pelajaran memadukan pembelajaran berbasis STL dan potensi lokal.

Kegiatan pengabdian pada masyarakat dengan program iptek bagi masyarakat ingin membantu guru-guru Sains dalam meningkatkan pengetahuan dan keterampilan dengan menerapkan pembelajaran berbasis STL dan potensi lokal untuk meningkatkan kualitas pembelajaran, dilaksanakan menjadi beberapa kegiatan, yaitu sosialisasi program, Penyuluhan, Pelatihan, Pendampingan, Desiminasi Hasil dan Membangun Teaching Networking Skills.

1) Tahap Sosialisasi, kegiatan sosialisasi rencana kegiatan dilakukan dalam rangka memberikan pemahaman, tujuan dan manfaat kegiatan yang akan dilakukan serta mengajak Guru Sains untuk mau dan ikut serta terlibat dalam kegiatan ini

2) Tahap Penyuluhan, kegiatan penyuluhan dilakukan berupa pemberian pemahaman secara ilmiah dengan pendalaman materi pelajaran memadukan pembelajaran berbasis STL dan potensi lokal dan menemukan permasalahan yang tidak bisa terpecahkan disekolah terkait dengan materi yang sulit, agar dapat mengembangkan pembelajaran aktif, inovatif, kreatif, efektif, dan menyenangkan.

3) Tahap Pelatihan, dari hasil pelaksanaan tahap penyuluhan yang memberikan informasi pembelajaran berbasis STL dan potensi lokal dan menemukan permasalahan yang tidak bisa terpecahkan disekolah, maka ditindak lanjuti dengan memilah dan karakteristik dari materi yang mudah sampai dengan materi pelajaran yang sulit. Pelatihan dengan menggunakan metode diskusi brainstorming melalui microteaching untuk memodelkan rancangan penggunaan pembelajaran berbasis STL dan potensi lokal diharapkan menciptakan pembelajaran aktif, inovatif, kreatif, efektif, dan menyenangkan.

4) Tahap Pendampingan, kegiatan pendampingan dalam pelaksanaan dikelas yang telah direncanakan pada tahap pelatihan. Pada kegiatan pendampingan melakukan identifikasi hambatan pelaksanan pembelajaran dalam praktiknya di kelas dan mengevaluasi perencanaan model pembelajaran berbasis STL dan potensi lokal pada setiap SMP-SMA yang mengikuti GURU Sains. 
5) Tahap Desiminasi Hasil dan Membangun Teaching Networking Skills, kegiatan desiminasi adalah kegiatan memberikan informasi tentang hasil yang diperoleh dari kegiatan pendampingan selama pelaksanan pembelajaran dalam praktiknya di kelas pada setiap SMP-SMA yang mengikuti guru Sains. Selain melakukan desiminasi, tim IbM juga membangun kerjasama dengan program Teaching Networking Skills, diharapkan dengan adanya bertukar pengalaman dan ilmu antara dosen-guru dalam bentuk "Guru Tamu", Dosen menjadi guru tamu di kelas pada materi tertentu sesuai bidang dan keahliannya. Tidak hanya berupa menjadi guru tamu, juga membimbing dalam pengetahuan teknologi dalam pembelajaran yang berbasis berbasis STL dan potensi lokal.

\section{HASIL DAN PEMBAHASAN}

Hasil pelaksanaan kegiatan pendampingan peningkatan kompetensi pedagogik guru sains SMP-SMA Negeri 1 Sesayap Kabupaten Tana Tidung melalui Science Technology Literacy (STL) dan pengembangan potensi lokal diuraikan dilakukan melalui beberapa tahap, yaitu: sosialisasi, penyuluhan, pelatihan, pendampingan, dan desiminasi hasil.

\section{Tahap Sosialisasi}

Tahapan sosialisasi merupakan kegiatan awal yang merupakan rencana kegiatan dalam rangka memberikan pemahaman, tujuan dan manfaat kegiatan yang akan dilakukan serta mengajak guru sains di SMP-SMA 1 Sesayap untuk mau dan ikut serta terlibat dalam kegiatan ini. Pada tahap sosialisasi ini diberikan gambaran singkat terkait tentang pentingnya penerapan Science Technology Literacy (STL) dan pengembangan potensi lokal. Jumlah guru yang hadir pada kegiatan sosialisasi awal sebanyak 10 orang guru sains SMP-SMA 1.

Berdasarkan Gambar 1 didapatkan hasil sebanyak 6 (60\%) guru sains belum memahami Science Technology Literacy (STL) dan pengembangan potensi lokal, 1 (10\%) orang guru memahami dan pernah melakukan pembelajaran berbasis Science Technology Literacy (STL) dan pengembangan potensi lokal, dan $3(30 \%)$ orang guru memahami, namun belum pernah menerapkan di kelas.

Berdasarkan data pemahaman guru terhadap STL dan pengembangan potensi lokal maka kemudian dilakukan wawancara kepada guru sains yang belum memahami STL dan pengembangan potensi lokal, dan guru yang memahami, namun belum pernah menerapkan. Wawancara berisi 
tentang metode yang dominan dilakukan oleh guru sains di kelas, berdasarkan hasil wawancara didapatkan hasil pada Gambar 2.
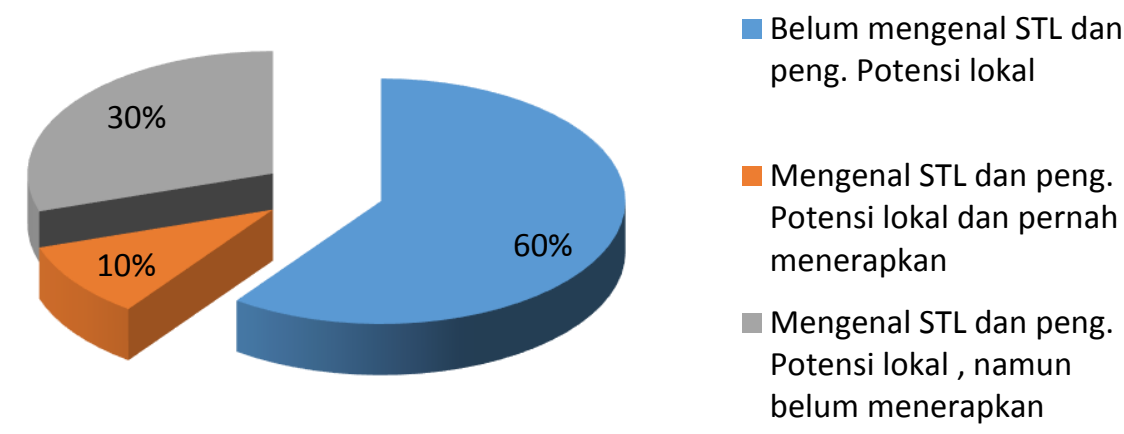

Gambar 1. Presentase Pengenalan Guru Sains SMP-SMA 1 Sesayap terhadap STL dan Pengembangan Potensi Lokal

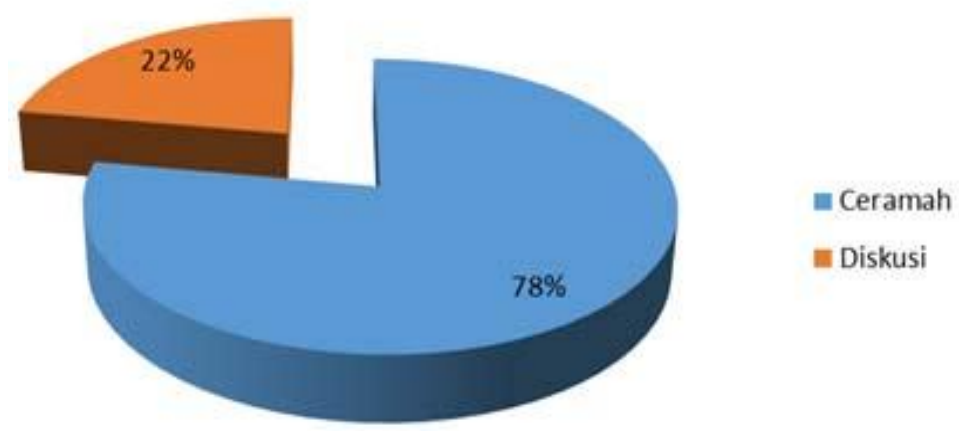

Gambar 2. Presentase Penggunaan Metode Pembelajaran oleh Guru Sains di SMP-SMA 1 Sesayap

Berdasarkan hasil data masih banyak guru sains yang menggunakan metode pembelajaran dengan menggunakan ceramah sebanyak $78 \%$. Minimnya penggunaan pembelajaran berbasis STL dan pengembangan potensi lokal merupakan salah satu alasan diperlukan adanya kegiatan pelatihan dan pendampingan guru untuk mengembangkan pembelajaran di kelas dengan berbasis STL dan pengembangan potensi lokal.

\section{Tahap Penyuluhan}

Kegiatan penyuluhan berisi pemberian pemahaman secara ilmiah dengan pendalaman materi pelajaran memadukan pembelajaran berbasis STL dan potensi lokal dan menemukan permasalahan yang tidak bisa terpecahkan 
disekolah terkait dengan materi yang sulit, agar dapat mengembangkan pembelajaran aktif, inovatif, kreatif, efektif, dan menyenangkan.

Pada tahapan penyuluhan ini didapatkan banyak pertanyaan oleh beberapa guru terutama pada terkait pemaduan pembelajaran STL dan potensi lokal dalam pembelajaran di kelas. Beberapa pertanyaan oleh guru pada tahap ini meliputi beberapa aspek yang digambarkan pada Tabel 1.

Berdasarkan pertanyaan yang diajukan oleh guru maka pertanyaan dijawab dan ditampung untuk bahan dalam tahapan pelatihan sekaligus penentuan materi yang akan dikembangkan menjadi pembelajaran berbasis STL dan pengembangan potensi lokal khususnya di Sesayap.

Tabel 1. Jenis Pertanyaan terkait Penerapan Pembelajaran Berbasis STL dan Pengembangan Potensi Lokal oleh Guru SMP-SMA 1 Sesayap

\begin{tabular}{lll}
\hline No. & \multicolumn{1}{c}{ Aspek } & \multicolumn{1}{c}{ Pertanyaan } \\
\hline & & a. $\begin{array}{l}\text { Bagaimana cara penerapan pembelajaran } \\
\text { berbasis STL dan pengembangan potensi lokal } \\
\text { di kelas? }\end{array}$ \\
& $\begin{array}{l}\text { Prosedur } \\
\text { Penerapan }\end{array}$ & $\begin{array}{l}\text { b. Apa saja hal yang perlu dipersiapkan dalam } \\
\text { penerapan pembelajaran berbasis STL dan } \\
\text { potensi lokal? }\end{array}$ \\
\hline 2 & Materi & $\begin{array}{l}\text { a. } \\
\text { Materi apa yang cocok dikembangkan pada } \\
\text { pembelajaran berbasis STL dan potensi lokal }\end{array}$ \\
\hline
\end{tabular}

Tabel 2. Pemilihan Materi dalam Pengembangan Pembelajaran Berbasis STL dan Pengembangan Potensi Lokal

\begin{tabular}{llcc}
\hline No & \multicolumn{1}{c}{ Materi } & Kelas & $\begin{array}{c}\text { Jumlah Guru yang } \\
\text { Mengembangkan }\end{array}$ \\
\hline 1 & $\begin{array}{l}\text { Keanekaragaman Mahluk Hidup } \\
\text { (SMP) }\end{array}$ & VII & 1 orang \\
\hline 2 & $\begin{array}{l}\text { Pertumbuhan dan Perkembangan } \\
\text { (SMP) }\end{array}$ & VIII & 1 orang \\
\hline 3 & Fotosintesis (SMP) & VIII & 1 orang \\
\hline 4 & Kemagnetan (SMP) & IX & 1 orang \\
\hline 5 & Alat-alat optic (Fisika SMA) & X & 1 orang \\
\hline 6 & Larutan Asam Basa (Kimia SMA) & XI & 2 orang \\
\hline 7 & $\begin{array}{l}\text { Keanekaragaman Hayati di } \\
\text { Indonesia (Biologi SMA) }\end{array}$ & $\mathrm{X}$ & 2 orang \\
\hline 8 & Ekosistem (Biologi SMA) & $\mathrm{X}$ & 1 orang \\
\hline
\end{tabular}

\section{Tahap Pelatihan}

Berdasarkan pelaksanaan tahap penyuluhan yang memberikan informasi pembelajaran berbasis STL dan potensi lokal dan menemukan 
permasalahan yang tidak bisa terpecahkan disekolah, maka ditindak lanjuti dengan memilah dan karakteristik dari materi yang akan dikembangkan menjadi pembelajaran berbasis STL dan pengembangan potensi Lokal. Berdasarkan hal ini maka dipilih materi yang digunakan berdasarkan pada Tabel 2.

Kegiatan pelatihan dilanjutkan dengan pembuatan perangkat (RPP dan Silabus) dan dilanjutkan dengan microteaching kepada sesama guru untuk memodelkan rancangan penggunaan pembelajaran berbasis STL dan potensi lokal.

\section{Tahap Pendampingan}

Tahap pendampingan dilakukan di kelas yang telah direncanakan pada tahap pelatihan. Pada kegiatan pendampingan melakukan identifikasi pelaksanaan pembelajaran melalui penerapan pembelajaran berbasis STL. Pada tahapan pendampingan ini didapatkan hasil guru bagus dalam penerapan STL, walaupun masih terdapat beberapa permasalahan teknis kecil, seperti: terkadang guru masih melihat materi di buku teks, pendampingan siswa terkadang tidak merata dilakukan oleh guru, dan permasalahan teknis kecil lainnya. Tabel 3 memuat deskripsi permasalahan dalam tahap pendampingan.

Tabel 3. Deskripsi Permasalahan dalam Tahap Pendampingan

\begin{tabular}{lll}
\hline No & Jenis Permasalahan & \multicolumn{1}{c}{ Deskripsi } \\
\hline 1 & Teknis pengajaran & $\begin{array}{l}\text { Beberapa guru masih ada yang sering melihat } \\
\text { kepada buku teks. }\end{array}$ \\
\hline 2 & $\begin{array}{l}\text { Ketidaksesuaian } \\
\text { dengan Perangkat }\end{array}$ & $\begin{array}{l}\text { Beberapa kegiatan dalam pembelajaran ada } \\
\text { yang tidak sesuai dengan perangkat terutama } \\
\text { pada tahapan apersepsi }\end{array}$ \\
\hline 3 & $\begin{array}{l}\text { Pendampingan } \\
\text { kepada siswa }\end{array}$ & $\begin{array}{l}\text { Beberapa guru terkadang hanya berpatokan } \\
\text { kepada beberapa siswa saja ketika siswa } \\
\text { melakukan diskusi kelompok }\end{array}$ \\
\hline
\end{tabular}

Pada tahap pendampingan proses pembelajaran di kelas guru juga memanfaatkan beberapa potensi lokal yang banyak di temukan di Kabupaten Tana Tidung, seperti pada materi keanekaragaman hayati guru membawa contoh beberapa tumbuhan yang ditemukan di daerah tersebut. Pada materi kemagnetan juga guru memberikan contoh penggunaan magnet dalam kehidupan sehari-hari dimasyarakat sekitar misalkan guru membawakan komponen sound dan membukanya menjadi beberapa bagian dan menunjukkan bagian yang terdapat magnet. Pada materi pertumbuhan dan perkembangan juga guru melakukan praktikum untuk mengetahui pengaruh cahaya terhadap pertumbuhan. 


\section{Tahap Desiminasi Hasil dan Membangun Teaching Networking Skills}

Kegiatan terakhir merupakan desiminasi adalah kegiatan memberikan informasi tentang hasil yang diperoleh dari kegiatan pendampingan selama pelaksanan pembelajaran dalam prakteknya di kelas pada setiap SMPSMA 1 Sesayap. Beberapa kesalahan teknis yang terjadi di tahap pendampingan dijabarkan secara rinci pada kegiatan desiminasi.

Selain melakukan desiminasi, tim IbM juga membangun kerjasama dengan program Teaching Networking Skills, diharapkan dengan adanya bertukar pengalaman dan ilmu antara dosen-guru dalam bentuk "Guru Tamu", Dosen menjadi guru tamu di kelas pada materi tertentu sesuai bidang dan keahliannya. Tidak hanya berupa menjadi guru tamu, juga membimbing dalam pengetahuan teknologi dalam pembelajaran yang berbasis berbasis STL dan potensi lokal

Berdasarkan hasil desiminasi didapatkan hasil bahwa guru sudah mampu menerapkan pembelajaran berbasis STL dan pengembangan potensi lokal. Pada awal kegiatan diidentifikasi guru yang tidak memahami STL dan pengembangan potensi lokal sebanyak $60 \%$ guru, dan yang pernah mengatahui namun tidak menerapkan sebanyak 30\% guru. Setelah dilakukan kegiatan pelatihan dan pendampingan sebanyak 10 guru sains di SMP-SMA 1 Sesayap sudah mampu menerapakan pembelajaran berbasis STL dan pengembangan potensi lokal di kelas.

\section{SIMPULAN}

Berdasarkan hasil dan pembahasan Ipteks bagi masyarakat didapatkan kesimpulan, yaitu: 1) Pada tahapan sosialisasi awal didapatkan hasil sebanyak 6 (60\%) guru belum memahami Science Technology Literacy (STL) dan pengembangan potensi lokal, 1 (10\%) orang guru memahami dan pernah melakukan pembelajaran berbasis Science Technology Literacy (STL) dan pengembangan potensi lokal, dan 3 (30\%) orang guru memahami, namun belum pernah menerapkan di kelas; 2) Permasalahan dalam penerapan pembelajaran STL dan pengembangan potensi lokal didapatkan hasil permasalahan banyak terdapat dari 3 aspek yaitu teknis pengajaran, kesesuaian dengan perangkat dan ketidakmerataan perhatian guru dalam pengelompokan siswa. Sementara itu, untuk penggunaan potensi lokal sudah sangat baik. Guru menggunakan beberapa benda, tumbuhan atau hewan yang ditemukan di daerah sekitar dalam pembelajaran di kelas; dan 3) Setelah dilakukan kegiatan pelatihan dan pendampingan sebanyak 10 guru sains di SMP-SMA 1 Sesayap sudah mampu menerapakan pembelajaran berbasis STL dan pengembangan potensi lokal di kelas. 
Pengenalan pendekatan, model, metode pembelajaran yang efektif dan inovatif perlu banyak dilakukan di daerah perbatasan. Permasalahan yang paling banyak ditemukan adalah kurang inovatif dan monotonnya pembelajaran yang dilakukan guru di daerah perbatasan. Peneliti selanjutnya diharapkan mampu memperkenalkan jenis model pembelajaran baru yang masih "asing" digunakan di daerah perbatasan.

Pengelolaan potensi lokal juga perlu diterapkan di sekolah kawasan perbatasan untuk mendukung pembelajaran yang kontekstual yang tidak hanya berpatokan kepada buku teks. Berdasarkan hal ini peranan pemerintah juga diperlukan dalam pengenalan potensi lokal kepada masyarakat sekitar sehingga bisa dijadikan bahan pembelajaran oleh guruguru di dalam kelas sekaligus mendukung tercapainya Standar Nasional Pendidikan pada BAB III pasal 14 ayat (1) yang menyatakan bahwa kurikulum SMP/MTs/SMPLB atau bentuk lain yang sederajat dan kurikulum untuk SMA/MA/SMALB atau bentuk lain yang sederajat dapat memasukkan pendidikan berbasis keunggulan lokal.

\section{REFERENSI}

Arofah, S. (2008). Peran guru dalam meningkatkan profesionalisme guru PAI SMP-SMA di Kabupaten Tegal. Skripsi. Fakultas Tarbiyah. IAIN Wali Songo. Semarang.

Depdiknas. (2008). SOP KKG dan GURU. Jakarta: Direktorat Jenderal Peningkatan Mutu Pendidik dan Tenaga Kependidikan Departemen Pendidikan Nasional.

Juwairiah. (2004). Profesionalisme guru dalam melaksanakan KKG dan GURU. [Online]. Tersedia: http://sumut.kemenag.go.id. [5 Oktober 2016].

Wiyono, K. (2009). Pembinaan profesionalisme guru IPA. Makalah. Sekolah Pascasarjana UPI.

\section{Ucapan Terimakasih}

Kami ucapkan kepada Rektor Universitas Borneo Tarakan yang telah memberikan kesempatan kepada dosen untuk melakukan pengabdian melalui dana DIPA pengabdian, tak lupa kepada Ketua LPPM, rekan dosen yang membantu dan guru-guru SMP-SMA Tidung Pale Kabupaten Tana Tidung yang berpartisipasi dalam pendampingan pembelajaran STL dan Pengembangan Potensi Lokal. 